\title{
Editorial Note for Journal of Astrophysics And Aerospace Technology
}

\section{Tarun Vinnakota* \\ Editor, Dayananda Sagar University, Department of Microbiology, India}

I am delighted to introduce Journal of Astrophysics \& Aerospace Technology (JAAT) provides the Half Yearly publication of articles in all areas related to Astrophysics, Nuclear Physics, Supernova Remnants, Fluid Mechanics, Quantum Gravity, Cosmology, Astrophysics, Blackholes, Cosmo particle Physics, Astrophysics \& Aerospace Technology. I am pleased to announce that, all issues of volume 13 were published online well within the time and the print issues were also brought out and dispatched within 30 days of publishing the issue online during the year of 2019.

As a member of Publisher International linking Association, PILA, Journal of Astrophysics \& Aerospace Technology follows the Creative Commons Attribution License and Scholars Open Access publishing policies. Journal of Astrophysics \& Aerospace Technology is the Council Contributor Member of Council of Science Editors (CSE) and following the CSE slogan Education, Ethics, and Evidence for Editors.

Journal of Astrophysics \& Aerospace technology maintains the highest standards of peer review while increasing the efficiency of the process. All the articles published in the journal will undergo full peer review. We will do our utmost to judge research objectively on its own merits and to avoid favouring research, for example, from particular institutions, countries, or regions. Key characteristics of the journal's review process are: All research articles submitted directly to the Journal are initially evaluated by assigned editor, and articles found appropriate for the Journal will be reviewed by at least two suitably qualified experts. Members of the editorial board lend insight, advice and guidance to the Editor-in-Chief generally and assist in decision making on specific submissions. The managing editor and editorial assistant provide administrative support to ensure Journal of Astrophysics \& Aerospace technology to maintain the integrity of peer review and delivers rapid and efficient publication to authors and reviewers.

All articles published by Journal of Astrophysics \& Aerospace Technology is open access: immediately freely available to read, download and share. All Journal of Astrophysics \& Aerospace Technology articles are published under the terms of the Creative Commons Attribution License which permits use, distribution and reproduction in any medium, provided the original work is properly cited.

I would also like to express my gratitude to all the authors, reviewers, the publisher, the advisory and the editorial board of Journal of Molecular and Genetic Medicine for their valuable support and we look forward to bring out the Volume 8 of Journal of Astrophysics \& Aerospace Technology in scheduled time. 
*Address for Correspondence: Tarun vinnakota, Editor, Dayananda sagar university, Department of Microbiology, India.

Copyright: () 2020 Tarun Vinnakota. This is an open-access article distributed under the terms of the Creative Commons Attribution License, which permits unrestricted use, distribution, and reproduction in any medium, provided the original author and source are credited.

Received 13 May 2020; Accepted 27 May 2020; Published 30 May 2020 